\title{
Synthesis and Characterization of Novel Low- $k$ Polyimides from Aromatic Dianhydrides and Aromatic Diamine Containing Phenylene Ether and Perfluorobiphenyl Units
}

\author{
Yasufumi Watanabe, Yuji Shibasaki, Shinji Ando, and Mitsuru UedA ${ }^{\dagger}$ \\ Department of Organic \& Polymeric Materials, Graduate School of Science and Engineering, \\ Tokyo Institute of Technology, 2-12-1, O-okayama, Meguro-ku, Tokyo 152-8552, Japan \\ (Received July 19, 2005; Accepted September 6, 2005; Published January 15, 2006)
}

\begin{abstract}
Novel fluorinated aromatic polyimides exhibiting very low dielectric constants were prepared from aromatic dianhydrides and aromatic diamines containing phenylene ether and perfluorobiphenyl units. Polycondensations were performed in 1-methyl-2-pyrrolidinone at room temperature for $18 \mathrm{~h}$, giving poly(amic acid)s with inherent viscosities up to $0.65 \mathrm{dL} / \mathrm{g}$. The poly(amic acid)s were converted to the corresponding polyimides by thermal treatment at $300{ }^{\circ} \mathrm{C}$ under nitrogen. The polyimides show low dielectric constants $(2.65-2.68)$ and high thermal stability $(5 \%$ weight loss temperatures are around $450^{\circ} \mathrm{C}$ ). [DOI 10.1295/polymj.38.79]

KEY WORDS Phenylene Ether / Polyimides / Thermal Properties / Refractive Index / Dielectric Constant /
\end{abstract}

Polyimides (PIs) are a class of polymers extensively used in microelectronics because of their outstanding key properties such as high thermal stabilities, chemical resistance, and good mechanical and excellent electrical properties. ${ }^{1}$ They have been used as interlayer dielectrics in integrated circuit fabrication. In microelectronic device circuits, the propagation velocity of the signal is inversely proportional to the square of the dielectric constant $(\varepsilon)$ of the propagation medium. Therefore, a low $\varepsilon$ material, which is called low $k$ material, is required to realize faster signal propagation and no crosstalk for new multi-level highdensity and high-speed electronic circuits. ${ }^{2}$

Recently, Goto et al. ${ }^{3,4}$ reported low $\varepsilon$ and thermally stable PIs containing fluorene structure. Introduction of aromatic bulky fluorene moieties is effective to decrease the $\varepsilon$ value with keeping the superior thermal stability. The observed low $k$ is attributable to the short aromatic $\pi$-conjugation length by the cardo aromatic structure and the lower imide group content per a repeating unit.

Based on the findings that poly(2,6-dimethyl-1,4phenylene ether) (PPE) shows a low $\varepsilon,{ }^{2,5}$ we developed one of the lowest $\varepsilon$ nonfluorinated PIs from the aromatic dianhydrides and the aromatic diamine containing phenylene ether linkages. ${ }^{6}$ Incorporation of fluorinated substituents in the PIs further lowers their $\varepsilon$ due to the low polarizability of C-F bond and the reduced intermolecular interactions due to the small dipole. ${ }^{1,7,8}$

This paper describes the synthesis and properties of aromatic PIs with the very low $\varepsilon$ from aromatic dianhydrides and the aromatic diamine containing phenylene ether and perfluorobiphenyl units.

\section{EXPERIMENTAL}

\section{Materials}

1-Methyl-2-pyrrolidinone (NMP) and N,N-dimethylformamide (DMF) were purified by the usual manner, and stored under nitrogen. Pyromellitic dianhydride (1a) and 4,4'-oxydiphthalic anhydride (1b) were purified by recrystallization from acetic anhydride and dried at $150{ }^{\circ} \mathrm{C}$ under vacuum before use. Other reagents and solvents were used as received.

\section{Measurements}

Infrared spectra (IR) were measured using a Horiba FT-210 spectrophotometer. ${ }^{1} \mathrm{H}$ nuclear magnetic resonance (NMR) spectra were recorded on a Bruker GPX300 (300 MHz) spectrometer. Thermogravimetry (TG) and differential scanning calorimetry (DSC) were performed on a Seiko TG/DTA 6300 and DSC 6200 , respectively, under nitrogen. Refractive indices of PI films formed on quartz substrates were measured at the wavelength of $1.320 \mu \mathrm{m}$ at room temperature with a Metricon model PC-2000 prism coupler. Using linearly polarized laser light with parallel (TE: transverse electric) and perpendicular (TM: transverse magnetic) polarizations to the film plane, the in-plane $\left(n_{\mathrm{TE}}\right)$ and out-of-plane $\left(n_{\mathrm{TM}}\right)$ refractive indices and the film thickness of the samples were determined. The $\varepsilon$ at the $1.0 \mathrm{MHz}$ frequency was calculated from the equation as follows: $\varepsilon=1.10 n_{\mathrm{AV}}^{2}$, where $n_{\mathrm{AV}}$ is an average refractive index (i.e., $\left.n_{\mathrm{AV}}=\left(2 n_{\mathrm{TE}}+n_{\mathrm{TM}}\right) / 3\right)$.

${ }^{\dagger}$ To whom correspondence should be addressed (E-mail: mueda@polymer.titech.ac.jp). 
Synthesis of 4-[2-(1-Methoxy-2,6-dimethylphenyl)isopropylidene]-2,6-dimethylphenol (2)

4,4'-Isopropylidenebis(2,6-dimethylphenol) (10.1 g, $35.6 \mathrm{mmol})$, iodomethane $(2.21 \mathrm{~mL}, 35.6 \mathrm{mmol})$, potassium carbonate $(10.3 \mathrm{~g}, 74.7 \mathrm{mmol})$, and acetone $(100 \mathrm{~mL})$ were refluxed for $24 \mathrm{~h}$ under nitrogen. After cooling the reaction mixture to room temperature, it was extracted with dichloromethane, and washed subsequently with $3 \mathrm{M} \mathrm{NaOH}$ aqueous solution to remove unconverted starting material. The solvents were evaporated, and the obtained solid was purified by silica gel column chromatography (toluene), to give a white-plate crystal after recrystallization from $n$-hexane. The yield was $4.48 \mathrm{~g}$ (42\%): $\mathrm{mp} 127-$ $128^{\circ} \mathrm{C}$. IR (KBr, v): 3460 ( $\left.\mathrm{Ar}-\mathrm{OH}\right), 2970,2870(\mathrm{C}-$ $\mathrm{H}), 2827\left(-\mathrm{OCH}_{3}\right), 1600,1489$ (Ar), $1188(\mathrm{C}-\mathrm{O})$ $\mathrm{cm}^{-1} .{ }^{1} \mathrm{H} \mathrm{NMR}\left(\mathrm{CDCl}_{3}, \delta, \mathrm{ppm}\right): 6.84$ (s, 2H), 6.82 (s, 2H), 4.48 (s, 1H), 3.70 (s, 3H), 2.23 (s, 3H), 2.20 $(\mathrm{s}, 3 \mathrm{H}), 1.59(\mathrm{~s}, 3 \mathrm{H})$. Anal. Calcd for $\left(\mathrm{C}_{20} \mathrm{H}_{26} \mathrm{O}_{2}\right): \mathrm{C}$, 80.50; H, 8.78. Found: C, 80.09; H, 8.53.

Synthesis of 4,4'-Bis\{4-[2-(1-methoxy-2,6-dimethylphenyl)isopropylidene]-2,6-dimethylphenoxylperfluorobiphenyl (3)

Compound 2 (5.51 g, $18.5 \mathrm{mmol})$, perfluorobiphenyl $(3.08 \mathrm{~g}, 9.23 \mathrm{mmol})$, potassium carbonate $(2.68 \mathrm{~g}$, $19.4 \mathrm{mmol})$, and acetone $(100 \mathrm{~mL})$ were refluxed for $52 \mathrm{~h}$ under nitrogen. The reaction mixture was allowed to cool to room temperature, and the mixture was then poured into water. The precipitate was collected by filtration and recrystallized from acetone to give white powder crystals. The yield was $5.35 \mathrm{~g}(65 \%)$ : mp 193-195 ${ }^{\circ} \mathrm{C}$. IR (KBr, v): 2966, $2873(\mathrm{C}-\mathrm{H}), 2827$ $\left(-\mathrm{OCH}_{3}\right), 1593,1481(\mathrm{Ar}), 1234(\mathrm{C}-\mathrm{F}), 1169$ (C-OC) $\mathrm{cm}^{-1} .{ }^{1} \mathrm{H} \mathrm{NMR}\left(\mathrm{CDCl}_{3}, \delta, \mathrm{ppm}\right): 6.90(\mathrm{~s}, 4 \mathrm{H}), 6.82$ $(\mathrm{s}, 4 \mathrm{H}), 3.71(\mathrm{~s}, 6 \mathrm{H}), 2.24(\mathrm{~s}, 12 \mathrm{H}), 2.21(\mathrm{~s}, 12 \mathrm{H}), 1.61$ (s, $12 \mathrm{H})$. Anal. Calcd for $\left(\mathrm{C}_{52} \mathrm{H}_{50} \mathrm{~F}_{8} \mathrm{O}_{4}\right): \mathrm{C}, 70.10 ; \mathrm{H}$, 5.66. Found: C, 69.73; H, 5.81.

Synthesis of 4,4'-Bis\{4-[2-(1-hydroxy-2,6-dimethylphenyl)isopropylidene]-2,6-dimethylphenoxy!perfluorobiphenyl (4)

A solution of $\mathbf{3}(5.08 \mathrm{~g}, 5.70 \mathrm{mmol})$ in dry $\mathrm{CH}_{2} \mathrm{Cl}_{2}$ $(30 \mathrm{~mL})$ was cooled to $-78^{\circ} \mathrm{C}$. Hereafter $\mathrm{BBr}_{3}(22.8$ $\mathrm{mL}, 22.8 \mathrm{mmol}$ in $\mathrm{CH}_{2} \mathrm{Cl}_{2}$ ) was added and the reaction mixture was allowed to warm to room temperature for $2 \mathrm{~h}$. The brown solution was cooled on ice and deionized water was slowly added. The organic layer was separated and the aqueous phase is extracted with $20 \mathrm{~mL}$ of $\mathrm{CH}_{2} \mathrm{Cl}_{2}$ twice. The combined organic layers were washed once with $50 \mathrm{~mL}$ of water, and dried with $\mathrm{MgSO}_{4}$ and concentrated. The crude material was recrystallized from acetone. The yield was 3.96g (81\%): $\mathrm{mp}$ 231-234 ${ }^{\circ} \mathrm{C}$. IR (KBr, v): 3602 (Ar-OH), 2970, 2870 (C-H), 1608, 1485 (Ar), 1203
(C-F), 1169 (C-O-C) $\mathrm{cm}^{-1} \cdot{ }^{1} \mathrm{H}$ NMR $\left(\mathrm{CDCl}_{3}, \delta\right.$, ppm): 6.90 (s, 4H), 6.81 (s, 4H), 4.49 (s, 2H, OH), $2.21(\mathrm{~s}, 12 \mathrm{H}), 2.20(\mathrm{~s}, 12 \mathrm{H}), 1.61(\mathrm{~s}, 12 \mathrm{H})$. Anal. Calcd for $\left(\mathrm{C}_{50} \mathrm{H}_{46} \mathrm{~F}_{8} \mathrm{O}_{4}\right)$ : C, 69.60; H, 5.37. Found: C, 69.81; H, 5.24.

Synthesis of 4,4'-Bis\{4-\{2-[(4-nitrophenoxy)-2,6-dimethylphenyl]isopropylidene\}-2,6-dimethylphenoxy\}perfluorobiphenyl (5)

A mixture of 4 (3.89g, $4.51 \mathrm{mmol})$, 4-chloro-1nitrobenzene $(1.56 \mathrm{~g}, 9.87 \mathrm{mmol})$, potassium carbonate $(1.36 \mathrm{~g}, 9.87 \mathrm{mmol})$, and dry DMF $(60 \mathrm{~mL})$ was refluxed for $15 \mathrm{~h}$ under nitrogen. The reaction mixture was allowed to cool to room temperature, and the mixture was then poured into water. The precipitate was collected by filtration and purified by silica gel column chromatography (toluene $/ n$-hexane $=4 / 3$ ). The yield was $2.33 \mathrm{~g}$ (yield $47 \%$ ): $\mathrm{mp} 130-132{ }^{\circ} \mathrm{C}$. IR (KBr, v): 2970, $2870(\mathrm{C}-\mathrm{H}), 1589,1485$ (Ar), 1520, $1342\left(\mathrm{NO}_{2}\right), 1246,1165(\mathrm{C}-\mathrm{O}-\mathrm{C}), 2850(\mathrm{C}-\mathrm{H}), 1531$ $\left(\mathrm{NO}_{2}\right), 1504(\mathrm{Ar}), 1346\left(\mathrm{NO}_{2}\right), 1238(\mathrm{C}-\mathrm{O}-\mathrm{C}) \mathrm{cm}^{-1}$. ${ }^{1} \mathrm{H}$ NMR $\left(\mathrm{CDCl}_{3}, \delta, \mathrm{ppm}\right): 8.18(\mathrm{~d}, J=9.3 \mathrm{~Hz}, 4 \mathrm{H}$, ArH), 6.95 (s, 4H), 6.93 (s, 4H), 6.85 (d, $J=9.0 \mathrm{~Hz}$, 4H, ArH), 2.23 (s, 12H), 2.06 (s, 12H), 1.67 (s, 12H). Anal. Calcd for $\left(\mathrm{C}_{62} \mathrm{H}_{52} \mathrm{~F}_{8} \mathrm{~N}_{2} \mathrm{O}_{8}\right)$ : C, 67.39; H, 4.74; N, 2.53. Found: C, 67.24; H, 5.10; N, 2.42 .

Synthesis of 4,4'-Bis\{4-\{2-[(4-aminophenoxy)-2,6-dimethylphenyl]isopropylidene $\}$-2,6-dimethylphenoxy\}perfluorobiphenyl (6)

Diamine (6) was synthesized according to modification by the catalytic reduction of dinitro compound $\mathbf{5}$. A mixture of $5(1.56 \mathrm{~g}, 1.41 \mathrm{mmol})$ and $0.061 \mathrm{~g}$ of $10 \%$ palladium on carbon $(\mathrm{Pd}-\mathrm{C})$ in $15 \mathrm{~mL}(N, N$-dimethylacetamide $(\mathrm{DMAc}) /$ ethanol $=3 / 1$ ) was stirred at $20^{\circ} \mathrm{C}$ under hydrogen for $24 \mathrm{~h}$. The solution was filtered to remove $\mathrm{Pd}-\mathrm{C}$, and the filtrate was poured into water. The precipitate was collected by filtration. The yield was $1.35 \mathrm{~g}$ (yield $92 \%$ ): $\mathrm{mp} 193-196^{\circ} \mathrm{C}$. IR (KBr, v): 3444, $3344\left(\mathrm{NH}_{2}\right), 2966,2870(\mathrm{C}-\mathrm{H}), 1608$, 1485 (Ar), 1230 (C-F), 1211, $1173(\mathrm{C}-\mathrm{O}-\mathrm{C}) \mathrm{cm}^{-1}$. ${ }^{1} \mathrm{H} \mathrm{NMR}\left(\mathrm{CDCl}_{3}, \delta, \mathrm{ppm}\right): 6.92(\mathrm{~s}, 4 \mathrm{H}), 6.89$ (s, 4H), $6.59(\mathrm{~s}, 8 \mathrm{H}), 3.33\left(\mathrm{~s}, 4 \mathrm{H}, \mathrm{NH}_{2}\right), 2.22(\mathrm{~s}, 12 \mathrm{H}), 2.08(\mathrm{~s}$, $12 \mathrm{H}), 1.65(\mathrm{~s}, 12 \mathrm{H})$. Anal. Calcd for $\left(\mathrm{C}_{62} \mathrm{H}_{56} \mathrm{~F}_{8} \mathrm{~N}_{2} \mathrm{O}_{4}\right)$ : C, 71.25; H, 5.40; N, 2.68. Found: C, 71.26; H, 5.51; $\mathrm{N}, 2.65$.

\section{Poly(amic acid)s (7a)}

A flame-dried $20 \mathrm{~mL}$ flask was charged with 6 $(0.672 \mathrm{~g}, 0.732 \mathrm{mmol})$ and NMP $(2.7 \mathrm{~mL})$ under nitrogen. 1a $(0.160 \mathrm{~g}, 0.732 \mathrm{mmol})$ was added to this solution at $20^{\circ} \mathrm{C}$ in one portion. The solution was stirred at this temperature for $18 \mathrm{~h}$ under nitrogen. The inherent viscosity of the resulting polymer was $0.38 \mathrm{dL} / \mathrm{g}$, measured at a concentration of $0.5 \mathrm{~g} / \mathrm{dL}$ in NMP at 


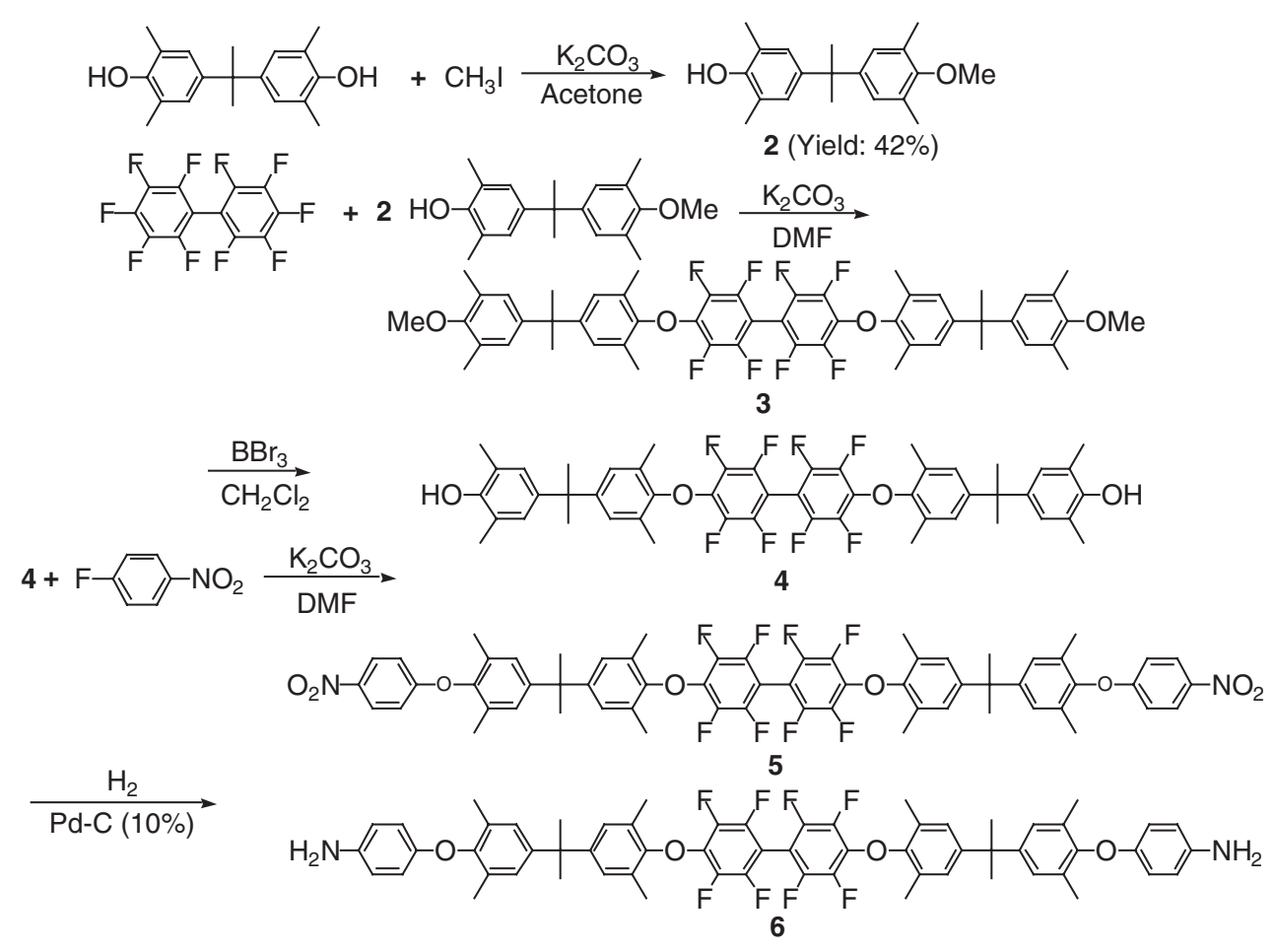

Scheme 1.

$30^{\circ} \mathrm{C}$. IR $(\mathrm{KBr}): v=1724(\mathrm{C}=\mathrm{O}$, carboxylic acid $)$, $1674(\mathrm{C}=\mathrm{O}$, amide $) \mathrm{cm}^{-1}$. Anal. Calcd for $\left(\mathrm{C}_{72} \mathrm{H}_{58^{-}}\right.$ $\left.\mathrm{F}_{8} \mathrm{~N}_{2} \mathrm{O}_{10}, 1.0 \mathrm{H}_{2} \mathrm{O}\right): \mathrm{C}, 67.50 ; \mathrm{H}, 4.72 ; \mathrm{N}, 2.19$. Found: C, 66.77; H, 5.08; N, 2.65.

\section{PIs $(8 a)$}

The PI film was prepared by casting the solution of polymer $7 \mathbf{a}$ on a silicon wafer at room temperature and then heating at $70^{\circ} \mathrm{C}$ for $1 \mathrm{~h}, 160^{\circ} \mathrm{C}$ for $1 \mathrm{~h}$, $250^{\circ} \mathrm{C}$ for $0.5 \mathrm{~h}$, and $300^{\circ} \mathrm{C}$ for $1 \mathrm{~h}$ under nitrogen. IR (KBr): $v=1778$ and 1732 (imide $\mathrm{C}=\mathrm{O}$ ), 1373 $(\mathrm{C}-\mathrm{N}) \mathrm{cm}^{-1}$. Anal. Calcd for $\left(\mathrm{C}_{72} \mathrm{H}_{54} \mathrm{~F}_{8} \mathrm{~N}_{2} \mathrm{O}_{8}\right)$ : C, 70.35; H, 4.59; N, 2.28. Found: C, 70.18; H, 4.69; $\mathrm{N}, 2.16$.

\section{RESULTS AND DISCUSSION}

\section{Monomer Synthesis}

Perfluorobiphenyl was selected as the fluorinated unit in the aromatic diamine because of the easy incorporation and good thermal stability. Furthermore, combining a previous finding, that is, the dilution effect of the polar imide groups by the phenylene ether group (a weight basis based on polymer) is effective to reduce the $\varepsilon$ value, aromatic diamine 6 containing both of phenylene ether and perfluorobiphenyl units was designed. Diamine 6 was prepared from $4,4^{\prime}$-isopropylidenebis(2,6-dimethylphenol) in five steps as shown in Scheme 1. Reaction of 4,4'-isopropylidenebis(2,6-dimethylphenol) with iodomethane in acetone gave 2, which was reacted with perfluorobiphenyl in

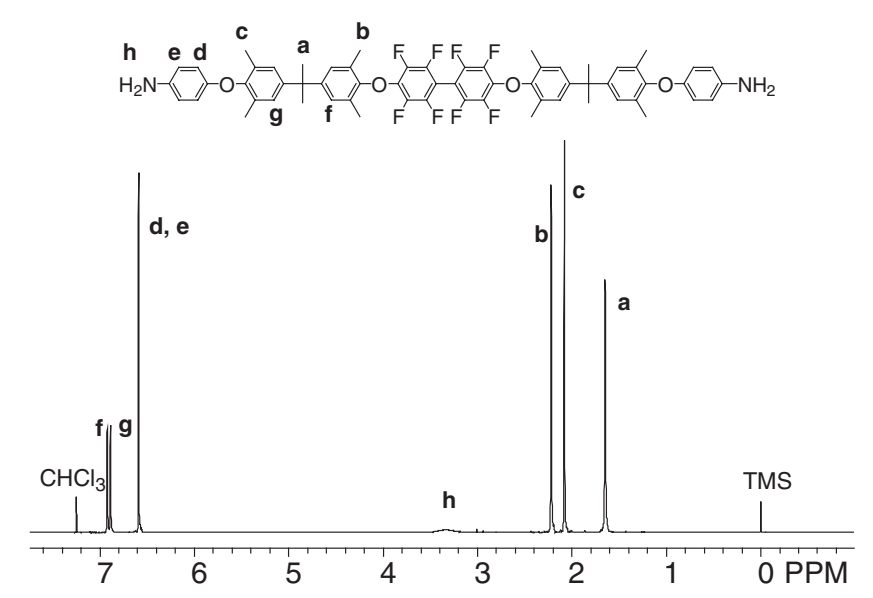

Figure 1. ${ }^{1} \mathrm{H}$ NMR spectrum of $\mathbf{6}$.

the presence of potassium carbonate in acetone to yield 3. Next, deprotection reaction of $\mathbf{3}$ with $\mathrm{BBr}_{3}$ in dichloromethane produced 4 . Then, condensation of 4 with 4-fluoro-1-dinitrobenzene in anhydrous DMF in the presence of potassium carbonate afforded $\mathbf{5}$, which was hydrogenated to give monomer $\mathbf{6}$. The structure of $\mathbf{6}$ was confirmed by IR and ${ }^{1} \mathrm{H}$ NMR spectroscopy. The IR spectrum of $\mathbf{6}$ shows characteristic absorptions of amino and ether groups at 3300 and $1200 \mathrm{~cm}^{-1}$, respectively. Elemental analysis also supported the formation of $\mathbf{6}$. The ${ }^{1} \mathrm{H}$ NMR spectrum of $\mathbf{6}$ is presented in Figure 1 together with the assignments of observed resonances. All peaks are well assigned to the expected structure of $\mathbf{6}$. 

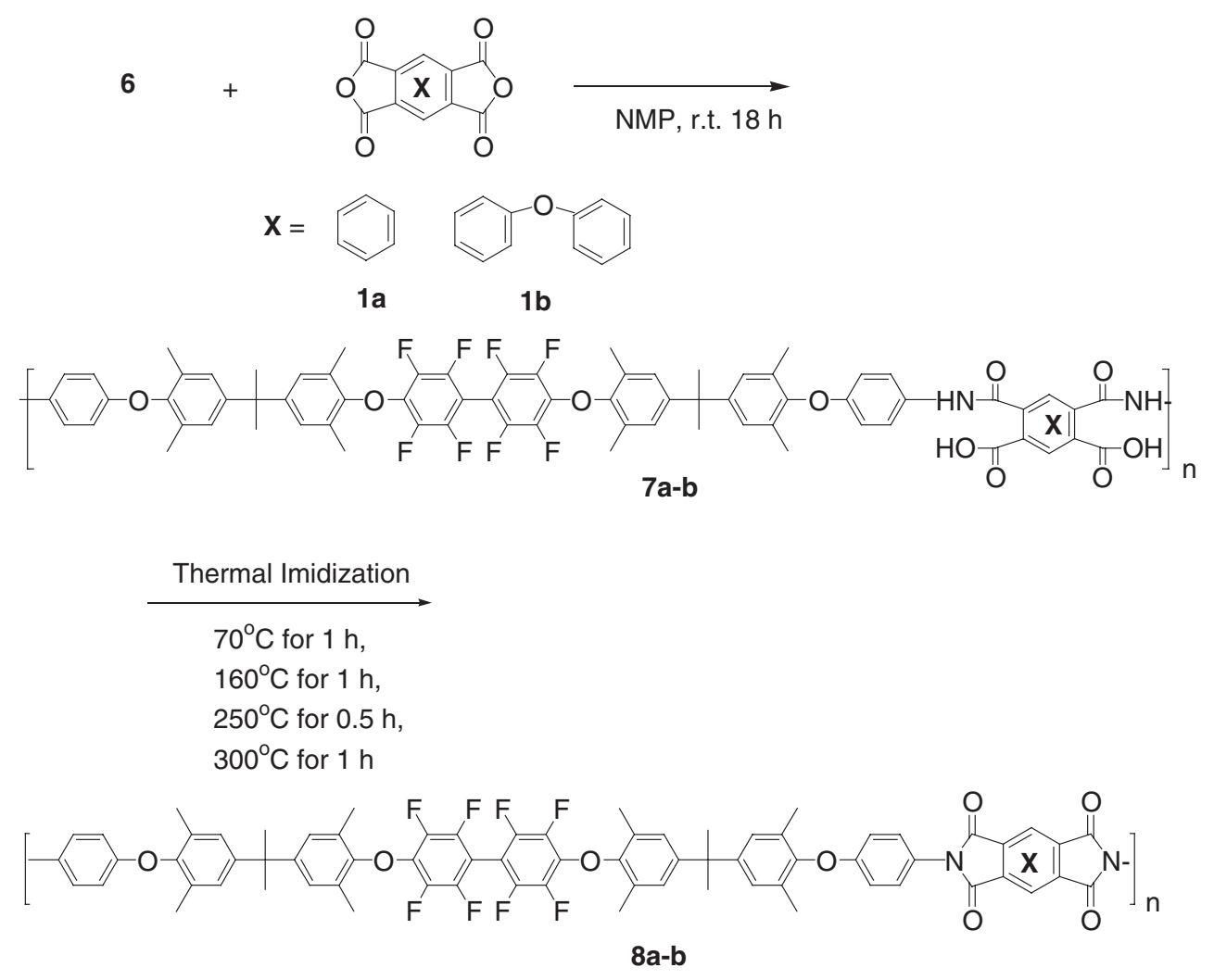

Scheme 2.

Table I. Synthesis of poly(amic acid) from $\mathbf{1}$ with $\mathbf{6}^{\mathrm{a}}$

\begin{tabular}{ccc}
\hline Dianhydride & Polymer & $\begin{array}{c}\text { Inherent Viscosity } \\
(\mathrm{dL} / \mathrm{g})^{\mathrm{b}}\end{array}$ \\
\hline $\mathbf{1 a}$ & $\mathbf{7 a}$ & 0.65 \\
$\mathbf{1 b}$ & $\mathbf{7 b}$ & 0.53 \\
\hline
\end{tabular}

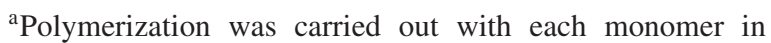
NMP at room temperature for $18 \mathrm{~h}$ under nitrogen. ${ }^{\mathrm{b}}$ Measured at a concentration of $0.5 \mathrm{~g} / \mathrm{dL}$ in NMP at $30^{\circ} \mathrm{C}$.

\section{Synthesis of Polymers}

As aromatic tetracarboxylic dianhydrides, 1a and 1b were employed as source materials. Polycondensations of diamines 6 with aromatic tetracarboxylic dianhydrides $\mathbf{1}(\mathbf{1 a}, \mathbf{1 b})$ were carried out in NMP at room temperature for $18 \mathrm{~h}$. The results are summarized in Table I. Polymerizations proceeded smoothly, giving poly(amic acid)s $\mathbf{7}$ (7a and $\mathbf{7 b}$ ) with relatively high inherent viscosities (Scheme 2).

\section{Characterization of Polymer}

The structures of $\mathbf{7}$ were identified as the expected poly(amic acid)s by IR spectroscopy that exhibited characteristic amide and carboxylic acid absorptions at $3345(\mathrm{~N}-\mathrm{H}$ and $\mathrm{O}-\mathrm{H}$ str), 1720 (acid, $\mathrm{C}=\mathrm{O}$ str), 1650 (amide, $\mathrm{C}=\mathrm{O}$ str), and $1540 \mathrm{~cm}^{-1}(\mathrm{~N}-\mathrm{H}$ bending).

Thermal conversion of 7a to $\mathbf{8 a}$ was performed by successive heating $7 \mathbf{a}$ to $300^{\circ} \mathrm{C}$ under $\mathrm{N}_{2}$. The IR

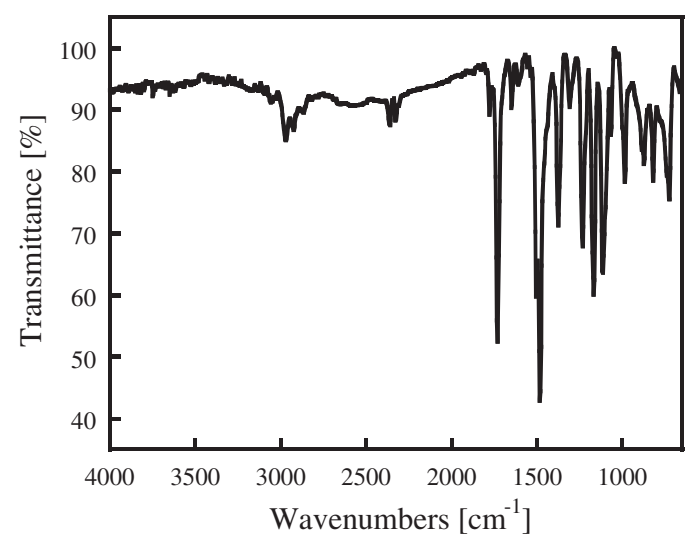

Figure 2. IR spectrum of thermally treated polymer $\mathbf{8 a}$ (film).

spectrum of thermally treated polymer 8a is shown in Figure 2, where characteristic imide absorptions at 1778 (asym $\mathrm{C}=\mathrm{O}$ str.), 1720 (sym $\mathrm{C}=\mathrm{O}$ str.), 1376 (C-N str.), and $744 \mathrm{~cm}^{-1}$ (imide ring deformation) are observed and the absorptions of amic acid groups have completely disappeared.

The thermal properties of the PIs evaluated by TG and DSC are summarized in Table II. The 5\% weight loss temperatures $\left(T_{5}\right)$ in nitrogen were observed around $450{ }^{\circ} \mathrm{C}$, which is similar to that of aromatic PIs containing phenylene ether units. ${ }^{6}$ The DSC trace of PI8a exhibited no endothermic peak and baseline shift due to melting point and glass transition, respec- 
Table II. Thermal properties of PIs

\begin{tabular}{cccc}
\hline PI & $T_{5}\left({ }^{\circ} \mathrm{C}\right)^{\mathrm{a}}$ & $T_{10}\left({ }^{\circ} \mathrm{C}\right)^{\mathrm{b}}$ & $T_{\mathrm{g}}\left({ }^{\circ} \mathrm{C}\right)^{\mathrm{c}}$ \\
\hline $\mathbf{8 a}$ & 450 & 460 & $-^{\mathrm{d}}$ \\
$\mathbf{8 b}$ & 450 & 470 & 223 \\
\hline
\end{tabular}

a $5 \%$ Weight loss temperature measured by TGA at heating rate of $10^{\circ} \mathrm{C} / \mathrm{min} .{ }^{\mathrm{b}} 10 \%$ Weight loss temperature measured by TGA at heating rate of $10^{\circ} \mathrm{C} / \mathrm{min}$. ${ }^{\mathrm{c}}$ Glass transition temperature measured by DSC at heating rate of $5{ }^{\circ} \mathrm{C} / \mathrm{min}$. ${ }^{\mathrm{d}} \mathrm{Not}$ observed.

tively. On the other hand, the glass transition temperature $\left(T_{\mathrm{g}}\right)$ of PI8b was clearly observed at $223^{\circ} \mathrm{C}$. These results show that the thermal stability and $T_{\mathrm{g}}$ are lower than those of wholly aromatic PIs, whereas they are sufficiently high in the fabrication processes of the components in microelectronics.

Polymers 7a and $\mathbf{7 b}$ were white solids and soluble in tetrahydrofuran, acetone, and polar aprotic solvents, such as $N, N$-dimethylacetamide (DMAc) and NMP at room temperature. High solubility of $\mathbf{7 a}$ and $\mathbf{7 b}$ compared to that of the corresponding nonfluorinated aromatic PIs containing phenylene ether units ${ }^{6}$ is explained by the low polarity of fluorine which induces the low cohesive energy. Transparent films were cast from DMAc solutions of polymers. In contrast PIs 8 were insoluble in organic solvents.

\section{Dielectric Constant of PIs}

The values of $\varepsilon$ for the polymer films at $1 \mathrm{MHz}$ were estimated from the refractive indices $(n)$ of the films according to a modified Maxwell's equation, $\varepsilon \fallingdotseq 1.10 n .^{9}$ The polymer films formed on quartz substrates were prepared via spin casting from DMAc and then converted to the corresponding PI films by thermal treatment. Table III summarizes the refractive indices and the $\varepsilon$ values of the PI films. The average refractive indices $\left(n_{\mathrm{AV}}\right)$ of $\mathbf{8} \mathbf{a}$ and $\mathbf{8 b}$ were determined as 1.5508 and 1.5623 , respectively. These were translated into $\varepsilon$ values of 2.65 , and 2.68 , respectively. These values are significantly lower than the optically estimated $\varepsilon$ of aromatic PIs containing phenylene ether units $(\varepsilon=2.74),{ }^{6}$ and comparable to that $(\varepsilon=$ 2.6) of the fluorinated PI (10FEDA/8FDOA) obtained from 1,4-bis(3,4-dicarboxytrifluorophenoxy)tetrafluorobenzene dianhydride (10FEDA) and 4,4'-oxybis-

Table III. Refractive indices and birefringence of PIs films

\begin{tabular}{ccccccc}
\hline PI & $\mathrm{d}(\mu \mathrm{m})^{\mathrm{a}}$ & $n_{\mathrm{TE}}{ }^{\mathrm{b}}$ & $n_{\mathrm{TM}}{ }^{\mathrm{c}}$ & $n_{\mathrm{AV}}{ }^{\mathrm{d}}$ & $\Delta n^{\mathrm{e}}$ & $\varepsilon^{\mathrm{f}}$ \\
\hline $\mathbf{8 a}$ & 3.8 & 1.5524 & 1.5477 & 1.5508 & 0.0047 & 2.65 \\
$\mathbf{8 b}$ & 3.3 & 1.5636 & 1.5598 & 1.5623 & 0.0038 & 2.68 \\
\hline
\end{tabular}

${ }^{\mathrm{a}}$ Film thickness. ${ }^{\mathrm{b}}$ In-plane refractive indices. ${ }^{\mathrm{c} O u t-o f}$ plane refractive indices. ${ }^{\mathrm{d}}$ Average refractive indices; $n_{\mathrm{AV}}=\left(2 n_{\mathrm{TE}}+\right.$ $\left.n_{\mathrm{TM}}\right) / 3 .{ }^{\mathrm{e}}$ Birefringence; $\Delta n=n_{\mathrm{TE}}-n_{\mathrm{TM}} \cdot{ }^{\mathrm{f}}$ Optically estimated dielectric constant; $\varepsilon=1.10 n_{\mathrm{AV}^{2}}$.

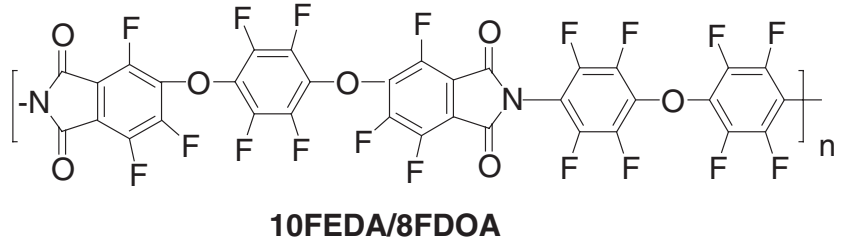

Scheme 3.

$\left(2,3,5,6\right.$-tetrafluoroaniline) $(8 \mathrm{FDOA})^{10} \quad$ (Scheme 3). This indicates that the incorporation of perfluorobiphenyl units into the main chain of PIs further decreased the $\varepsilon$ values without sacrificing the thermal stability. The in-plane/out-of plane birefringences $(\Delta n)$ of $\mathbf{8 a}$ and $\mathbf{8 b}$ are 0.0047 and 0.0038 , respectively, which are comparable to those (0.0042 and 0.0049) of aromatic PIs containing phenylene ether units, ${ }^{6}$ and far lower than those of conventional aromatic PIs. The dilution effect of the polar imide ring might cause a weak interaction between polymers, resulting in lower $\Delta n$ in $\mathbf{8 a}$ and $\mathbf{8 b}$. The absence of birefringence was also reported for alicyclic PIs. ${ }^{11,12}$

\section{CONCLUSIONS}

PIs 8a and 8b with high molecular weights were prepared from aromatic dianhydrides and aromatic diamine containing phenylene ether and perfluorobiphenyl units, and exhibited the very low $\varepsilon$ and good thermal stability. The incorporation of the perfluorobiphenyl unit accompanying with a phenylene ether unit in PI main chains effectively reduces the $\varepsilon$ values while maintaining their thermal stability. The $\varepsilon$ values of the obtained PIs reached to the $\varepsilon$ of perfluorinated PI (10FEDA/8FDOA).

\section{REFERENCES}

1. "Polyimides Fundamentals and Applications," M. K. Ghosh, K. L. Mittal, and K. L., Ed., Marcel Decker, New York, 1996.

2. G. Maier, Prog. Polym. Sci., 26, 3 (2001).

3. K. Goto, M. Kakuta, Y. Inoue, and M. Matsubara, J. Photopolym. Sci. Technol., 13, 313 (2000).

4. K. Goto, Y. Inoue, and M. Matsubara, J. Photopolym. Sci. Technol., 14, 33 (2001).

5. R. H. Vora, P. S. G. Krishnan, S. H. Goh, and T. S. Chung, Adv. Funct. Mater., 11, 361 (2001).

6. Y. Watanabe, Y. Shibasaki, S. Ando, and M. Ueda, Polymer, 46, 5903 (2005).

7. K. Goto, in "Polyimides," Y. Imai and R. Yokota, Eds., N.T.S, Tokyo, 2002, p 270.

8. C.-Y. Yang, H.-C. Chian, and Y.-Y. Su, Polym. J., 36, 979 (2004).

9. D. Boese, H. Lee, D. Y. Yoon, J. D. Swallen, and J. F. Rabolt, J. Polym. Sci., Part B: Polym. Phys., 30, 1321 


\section{Y. WATANABE et al.}

(1992).

10. S. Ando, T. Matsuura, and S. Sasaki, in "Polymers for Microelectronics: Resists and Dielectrics," L. F. Thompson,

C. G. Willson, and S. Tagawa, Ed., American Chemical
Society, Washington, D.C., 1994, p 304.

11. T. Matsumoto, Macromolecules, 32, 4933 (1999).

12. Y. Watanabe, Y. Sakai, Y. Shibasaki, S. Ando, M. Ueda, Y. Oishi, and K. Mori, Macromolecules, 35, 2277 (2002). 